\title{
Subependymal Hemorrhage
}

National Cancer Institute

\section{Source}

National Cancer Institute. Subependymal Hemorrhage. NCI Thesaurus. Code $C 99065$.

Bleeding within the subependymal germinal matrix. 